\title{
Thermomechanical errors in a horizontal in-place inclinometer
}

\author{
SJ Clarke Pells Sullivan Meynink, Australia
}

\begin{abstract}
A recent tunnelling project in Sydney involved the installation of an $80 \mathrm{~m}$ long horizontal in-place inclinometer (IPI), comprising 40 tilt sensors, each with a gauge length of $2 \mathrm{~m}$. This was intended to provide real-time monitoring of the crown deformation during tunnel construction beneath a major highway.

Upon commencement of tunnelling, the monitoring data was found to include significant errors, to the extent that it did not provide any useful deformation data during the duration of the project. The instrument was replaced by alternate monitoring strategies. The cause of the problem was unresolved.

This type of monitoring system and IPI instrumentation had previously been used successfully by the same installer, though in vertical installations.

Upon completion of the project, further investigations were undertaken to understand the problem. A mechanism was proposed in which the extension bars linking the instruments were bent due to changes in temperature. This behaviour is only possible if the IPIs are constrained from axial movement along the inclinometer casing, and results in a real tilt of the instrument sensor which is independent of the deformation of the casing. The sensor would therefore indicate movement that does not represent that of the casing.
\end{abstract}

Numerical modelling was undertaken to simulate this effect. This indicated a sensitivity to temperature changes which was similar to the field measurements.

Additional experimentation in a laboratory environment was undertaken to verify the mechanism. Measurements of wheel friction confirmed that the instruments were subject to significant axial restraint, especially where multiple instruments were connected together.

The errors observed in the tunnel project were therefore attributed to two main factors:

- Friction between the wheels of the instrument and the inclinometer casing, which effectively restrained axial movement. This factor was exacerbated by the large number of instruments employed.

- Significant temperature variations experienced during tunnel construction (up to $13^{\circ} \mathrm{C}$ ).

Modifications to the instrument design and installation procedures are proposed to prevent this problem from recurring.

\section{Introduction}

Construction of the South West Rail Link (SWRL) project in the southern suburbs of Sydney involved excavation of an $80 \mathrm{~m}$ long tunnel beneath the Hume Highway. The tunnel was designed by SMEC Australia Pty Ltd, and built by the John Holland Group between 2011 and 2013. The author was involved as a technical advisor to the Roads and Maritime Authority of New South Wales (RMS), who own and operate the highway.

Geotechnical instrumentation included a horizontal in-place inclinometer (IPI). This was installed prior to the commencement of tunnel excavation. The IPI was grouted inside the central canopy tube which ran the full length of the tunnel (Figure 1). 
The IPI was installed and monitored by Lynton Survey Pty Ltd, who had successfully used similar devices in vertical boreholes. Data obtained from the horizontal IPI proved erratic and indicated movement far in excess of that considered realistic (based on results from other monitoring devices). The cause of the problems could not be resolved at the time of construction. The instrument was ultimately abandoned and replaced by additional in-tunnel survey monitoring.

For those aware of these issues, including the RMS, these problems have meant that future use of this type of monitoring instrument is unlikely until the cause is understood and a remedy available to prevent its recurrence. This paper provides both an explanation as to the cause of the problems, and presents recommendations to prevent it from occurring in future installations.

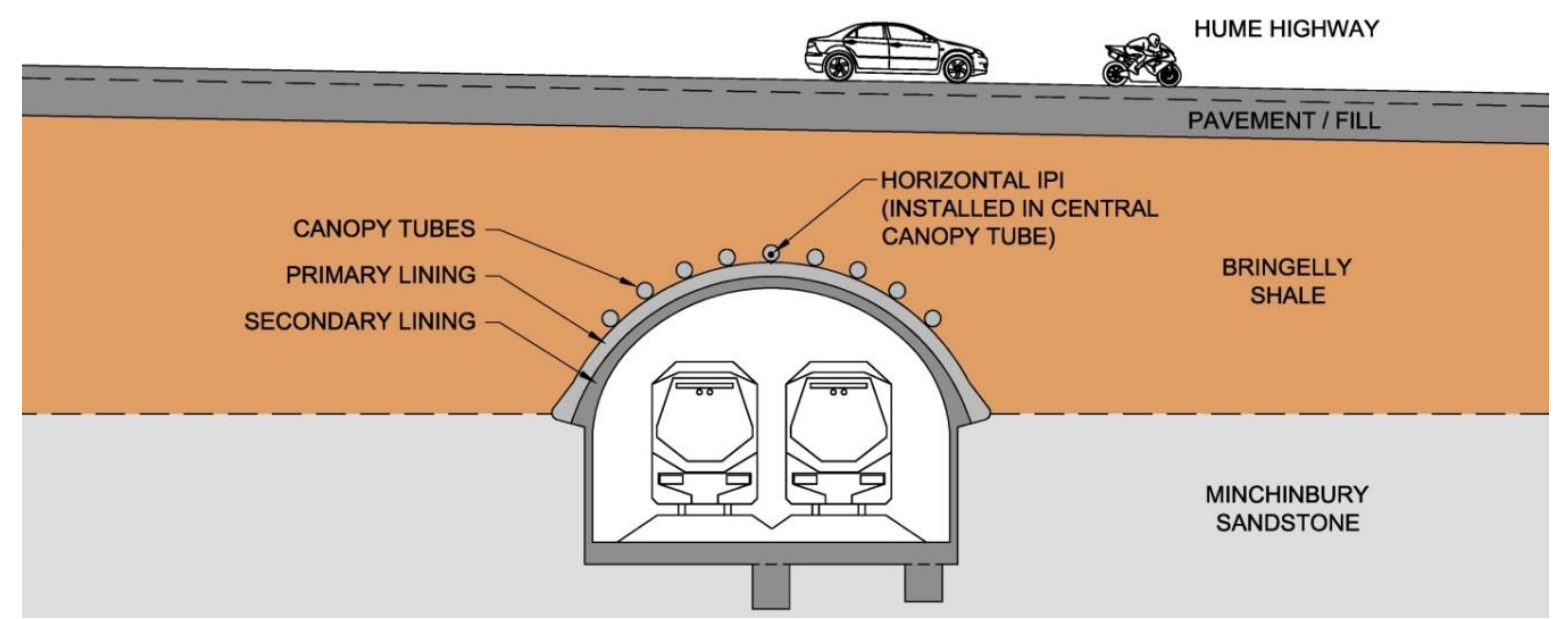

Figure 1 The horizontal IPI ran along the tunnel crown over the full length of the tunnel

\section{Instrument details}

The IPI installation involved 40 instruments connected together to form a continuous 'string' of $80 \mathrm{~m}$ length. Extension tubes connecting the instruments were used to achieve a gauge length of $2.0 \mathrm{~m}$ (i.e. the distance between the wheels). The tubes are of stainless steel construction, with an outside diameter of $12.7 \mathrm{~mm}$ and a wall thickness of $1.2 \mathrm{~mm}$.

The instruments were manufactured by Slope Indicator Inc. and utilised micro electro-mechanical systems (MEMS) tilt sensors. Each instrument also included a thermistor for measuring temperature. The instruments are connected in series, such that a single cable services all of the instruments.

The IPI was installed within standard $70 \mathrm{~mm}$ diameter inclinometer casing.

During installation, two men were required to push the instruments into the casing.

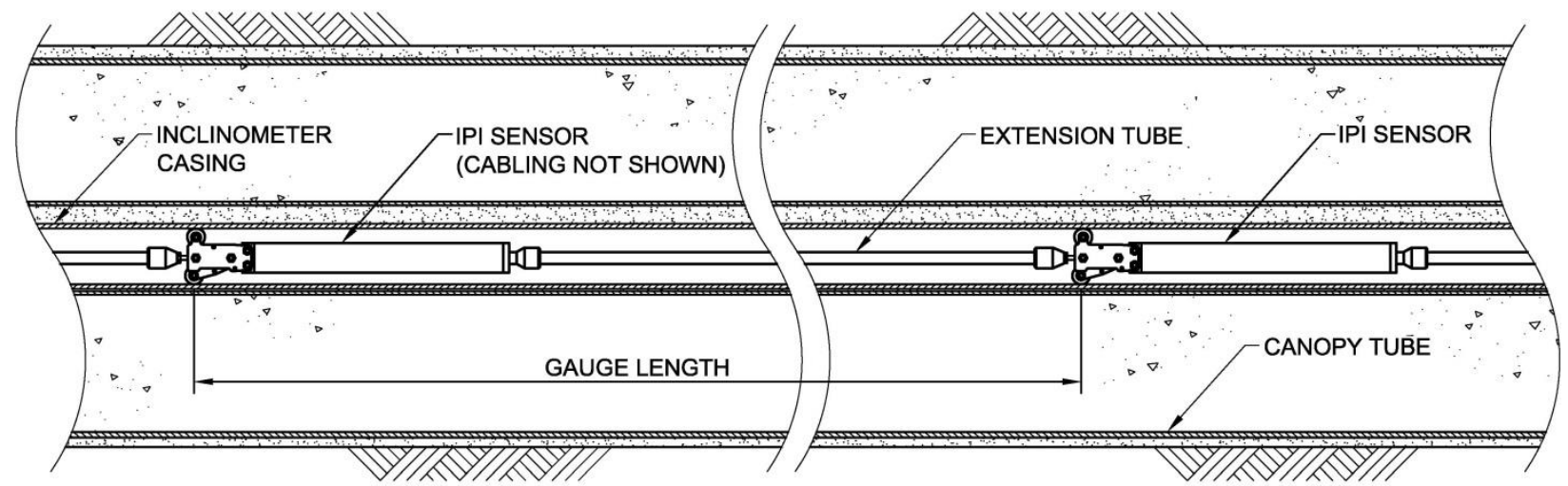
Figure 2 The horizontal IPI was installed within the central $406 \mathrm{~mm}$ diameter steel canopy tube


Each sensor has its own calibration certificate, which includes temperature corrections. The temperature corrections relate only to the sensitivity of the MEMS sensor, and do not account for the mechanical response to temperature described in this paper.

The instruments were connected to a data logger which recorded tilt and temperature at five-minute intervals. The instrument was operational between October 2012 and February 2013, with measurements commencing about three weeks prior to the commencement of tunnelling.

\section{$3 \quad$ Monitoring data}

The IPI sensors provided consistent results and appeared to be functioning correctly in the weeks leading up to the start of tunnelling.

Upon the commencement of tunnel excavation, results indicated movement that conflicted with other monitoring data. As tunnelling progressed, the problems increased until the results were deemed useless. On 19 January 2013 a cumulative vertical deviation of $345 \mathrm{~mm}$ was indicated, which was far in excess of expected and observed values. At this time, the tunnel was almost complete, and the temperatures measured by the sensors were relatively high (up to $33^{\circ} \mathrm{C}$ ). The instrument was essentially abandoned, with its function replaced by other monitoring approaches. Survey data indicated a ground surface heave of up to $25 \mathrm{~mm}$ at the end of tunnel construction (Clarke \& Walker 2014).

Figure 3 summarises temperature data from the 40 sensors over the duration of the tunnelling works. This shows that the temperature of each sensor was stable until the tunnel excavation passed beneath it, upon which they experienced significant variations in temperature. From the figure, it is apparent that most of the sensors experienced similar temperatures. Over the duration of the project, the sensors recorded temperatures of between $19^{\circ} \mathrm{C}$ and $33^{\circ} \mathrm{C}$. By comparison, air temperature recorded at a nearby weather station indicated a range from $18^{\circ} \mathrm{C}$ to $46^{\circ} \mathrm{C}$ over the same period. The sensors also appear to have experienced elevated temperatures from the exothermic reaction associated with hydration of the shotcrete which was sprayed against the underside of the canopy tubes. 


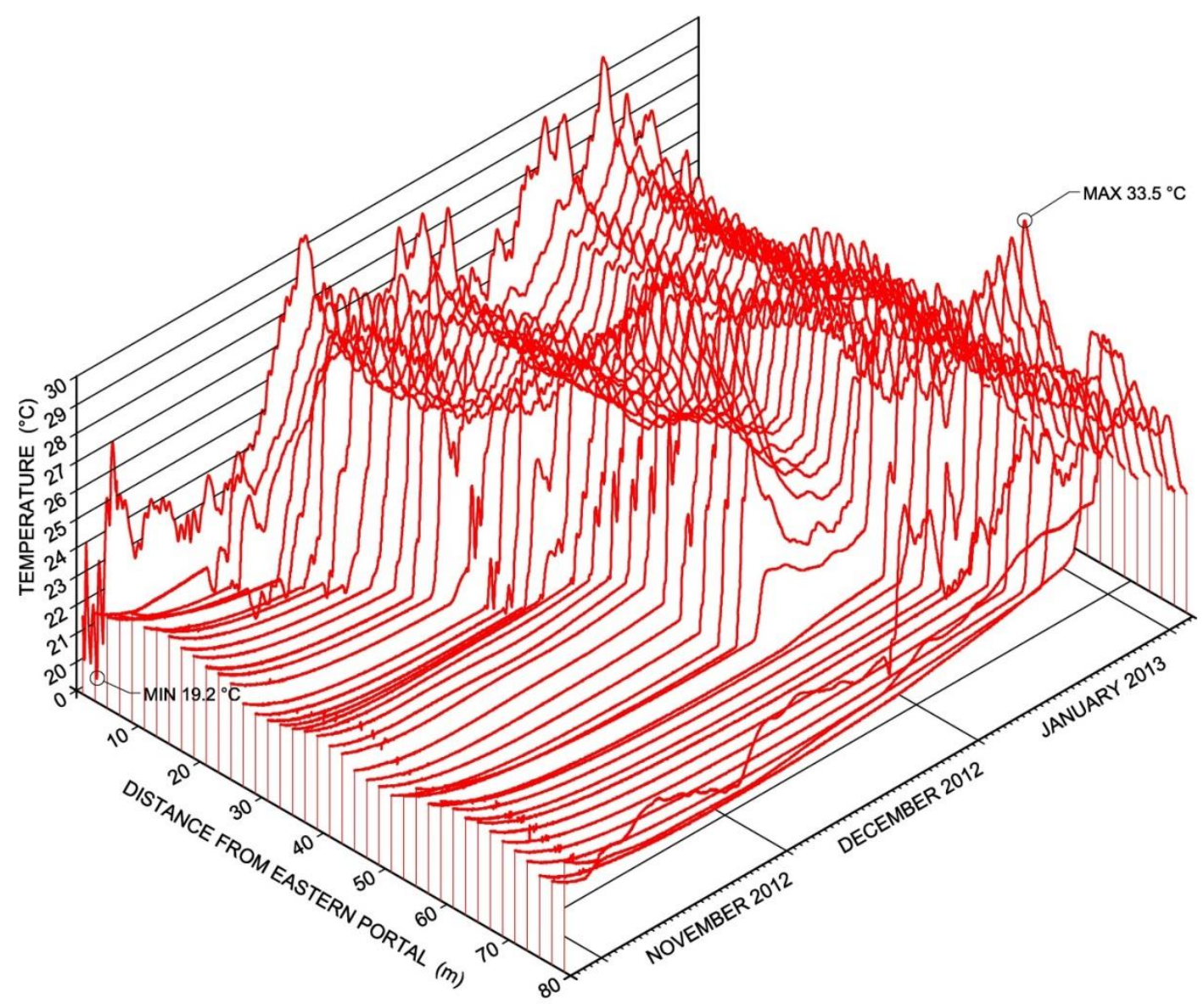

Figure 3 Temperature data measured by each of the 40 sensors between October 2012 and February 2013, indicating relatively stable conditions prior to the tunnel face reaching each sensor

\section{$4 \quad$ Possible explanations}

The instrument subcontractor consulted with the manufacturer to try and resolve the problem, but without success.

The tunnel designer noted that the horizontal IPI proved unreliable due to the measurements being influenced by the excavation activities (Hill et al. 2014). These activities included the use of hydraulic impact breakers to excavate the tunnel which resulted in significant vibration.

Towards the end of the project, Lynton Survey postulated a mechanism associated with temperature changes that resulted in a physical change to the instrument geometry. It is this mechanism that has been investigated in this paper.

\section{$5 \quad$ Review of monitoring data}

Well after the completion of the project the horizontal IPI data was reviewed to assess the explanation proposed by Lynton Survey.

The 2012 Christmas shutdown provided an opportunity to examine the data without the additional complications posed by the various construction activities. The shutdown was from 21 December 2012 to 7 January 2013. During this period deformation associated with tunnelling development and construction stopped (based on the real-time automated surface survey monitoring, also operated by Lynton Survey), there was no vibration from the impact breakers, and no shotcrete was sprayed. The air temperature, however, continued to fluctuate. 
Figure 4 summarises the temperature and tilt data recorded during this period relative to the position of each instrument along the tunnel alignment. This shows that the sensors located above the excavated part of the tunnel experienced a temperature range of approximately $8^{\circ} \mathrm{C}$, whereas those sensors which were still surrounded by rock recorded relatively stable temperatures.

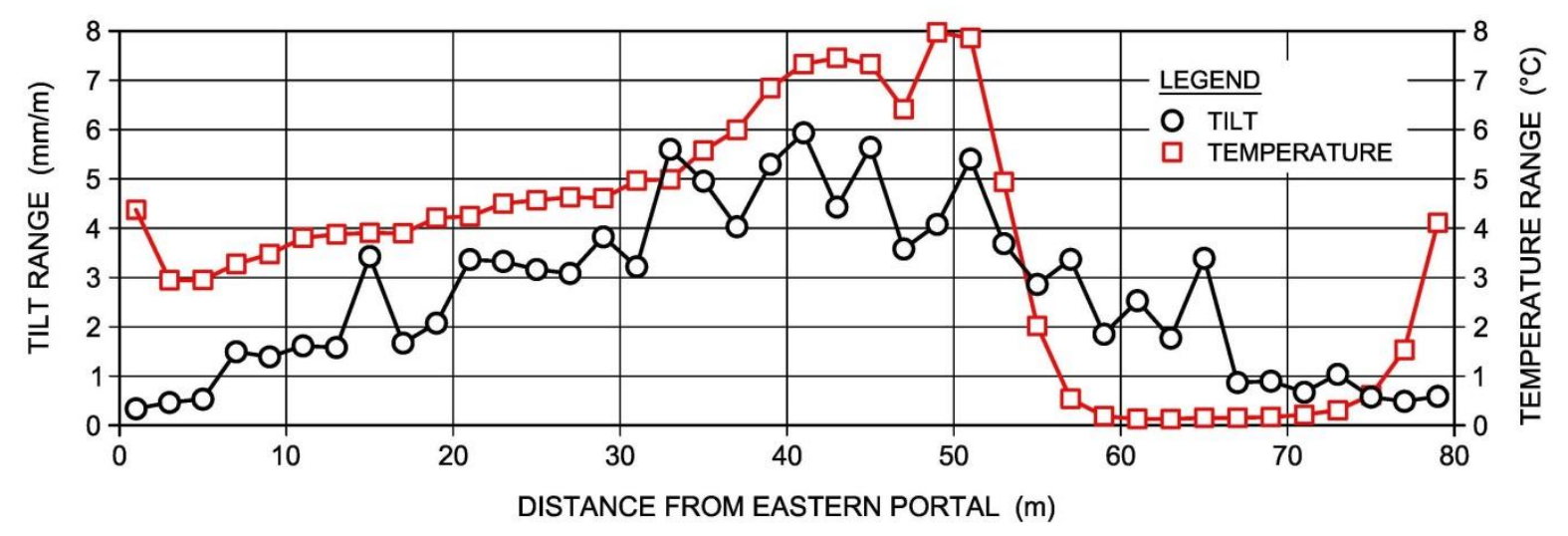

Figure 4 Tilt and temperature data measured during the Christmas break

The figure also shows the range of tilt values measured during this period, and shows a greater range towards the centre of the tunnel compared to that measured at each portal. Note that other monitoring instruments indicate no movement during this period, such that this apparent change of tilt occurred independently of ground movement. This triangular distribution of tilt is consistent with the wheel friction issues discussed in Section 8.2.

Figure 5 presents a graph of tilt versus temperature for the sensors located within the excavated portion of the tunnel. It indicates an approximately linear correlation, with slopes of between $0.64 \mathrm{~mm} / \mathrm{m} /{ }^{\circ} \mathrm{C}$ and $1.17 \mathrm{~mm} / \mathrm{m} /{ }^{\circ} \mathrm{C}$. The correlation was absent or much weaker for the instruments located at or near the portal. 


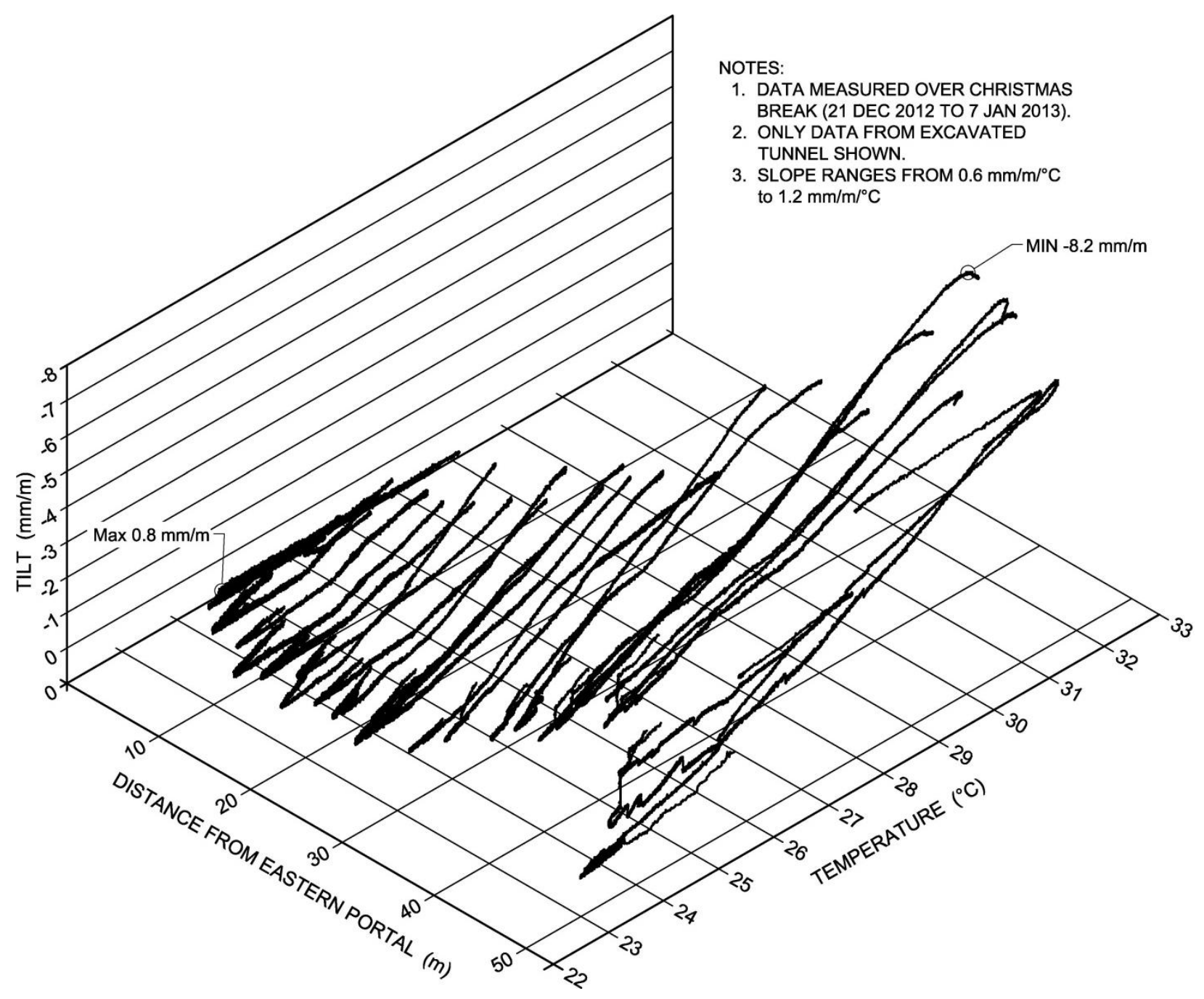

Figure 5 Measured tilt versus temperature during the Christmas break

\section{Thermomechanical mechanism}

Based on the monitoring data recorded during the Christmas shutdown, it was apparent that the tilt indicated by the IPI sensors was sensitive to changes in temperature. The hypothesis proposed by Lynton Survey was that this was a real change in the tilt experienced by the sensor, but independent of movement of the inclinometer casing, and not associated with changes in the sensitivity of the MEMS sensor (which is addressed by a separate calibration and correction).

Thermal expansion of the instruments was expected to result in bending of the extension rods, but only if the instruments were restrained from movement in the axial direction. The observation from the installer that two men were required to push the sensors into place demonstrates that there was a significant amount of friction between the wheels and casing, such that the mechanism was considered feasible.

The fact that the instruments are manufactured from stainless steel is also relevant, as its coefficient of thermal expansion is relatively high (about $50 \%$ greater than that of mild steel).

The following section presents structural modelling developed to explore this mechanism, in particular to assess whether it results in the same change in tilt as indicated by the field measurements shown in Figure 5. 


\section{$7 \quad$ Structural modelling}

Structural modelling of a single IPI instrument was undertaken using the analysis package Microstran, produced by Engineering Systems Pty Ltd. This package is capable of analysing thermal expansion, and nonlinear effects such as node coordinate updating and axial shortening.

The IPI instrument was modelled as a series of tubes corresponding to the actual instrument details, with the ends restrained by pinned connections. The model included the weight of the instrument as well as that of the signal cable which is supported by the sensor and extension tube. The model was run for temperature increases of up to $15^{\circ} \mathrm{C}$. It is noted that this temperature change result in an extension of about $0.4 \mathrm{~mm}$ for a $2 \mathrm{~m}$ long unrestrained instrument.

The calculated vertical deflection of the instrument due to self-weight was $7 \mathrm{~mm}$ (without axial restraint, and with no axial force applied).

Tilt was calculated from deflection of the portion of model where the MEMS sensor is located. No initial axial force was applied.

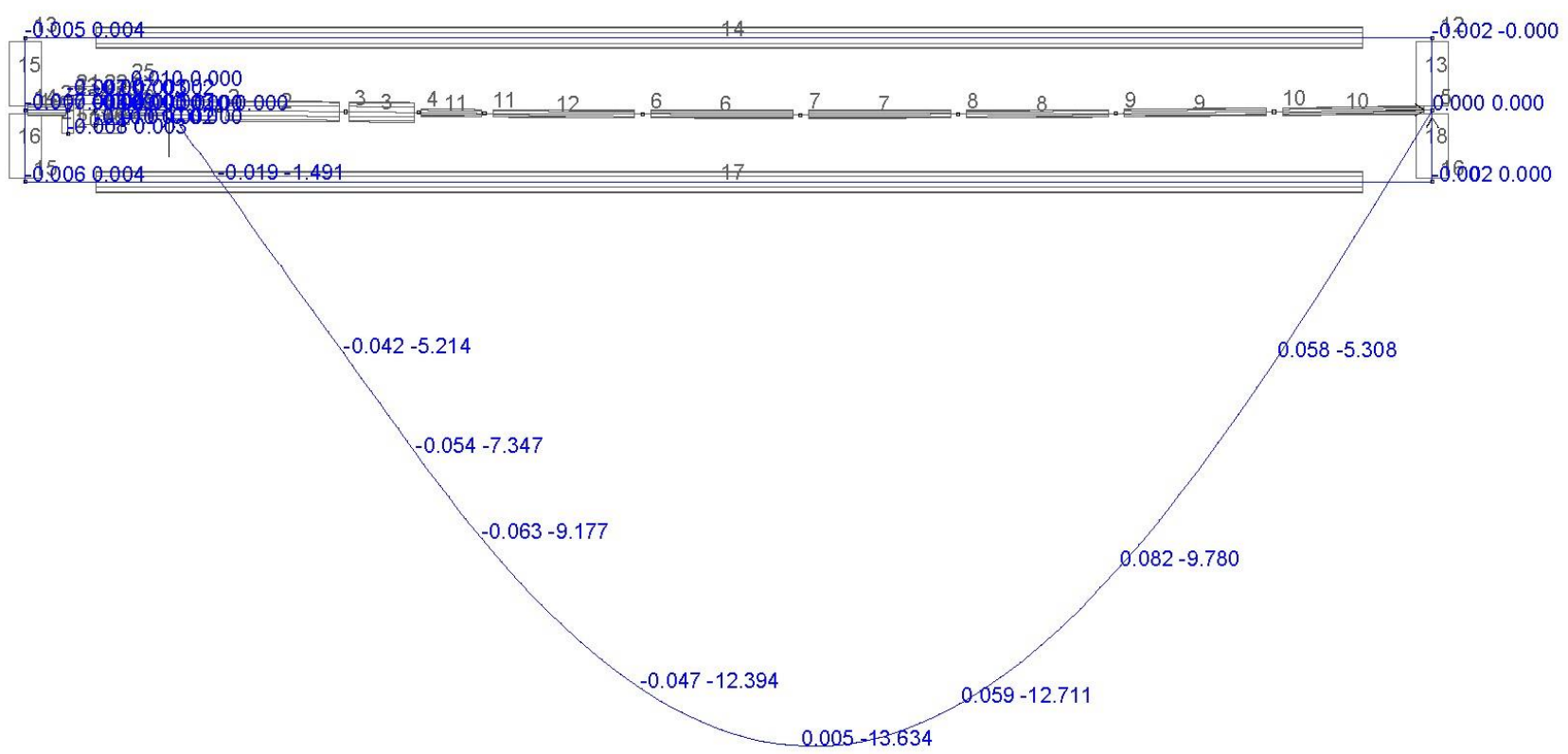

Figure 6 Structural model used to investigate the effect of temperature changes. Also shown is the loading frame used in the laboratory work

Results are summarised in Figure 7. This shows a non-linear response, with a calculated change in tilt of up to $19 \mathrm{~mm} / \mathrm{m}$ for a temperature increase of $15^{\circ} \mathrm{C}$. The figure also presents the calculated axial force induced in the instrument assembly as a result of the restrained thermal expansion. Up to $230 \mathrm{~N}$ compressive force is calculated.

The maximum tilt corresponds to a midspan deflection of $14 \mathrm{~mm}$ (not including the initial deflection under self-weight).

The sensitivity to increases in temperature was calculated and was found to range from $1.0 \mathrm{~mm} / \mathrm{m} /{ }^{\circ} \mathrm{C}$ (for high initial axial compressive force) to $1.7 \mathrm{~mm} / \mathrm{m} /{ }^{\circ} \mathrm{C}$ (no initial axial force). These values are a little higher than the field results shown in Figure 5. However, the higher values are unlikely to be observed because either the wheels would slip as the load increases, or if constrained the sensitivity reduces with increasing load (as per Figure 7). 


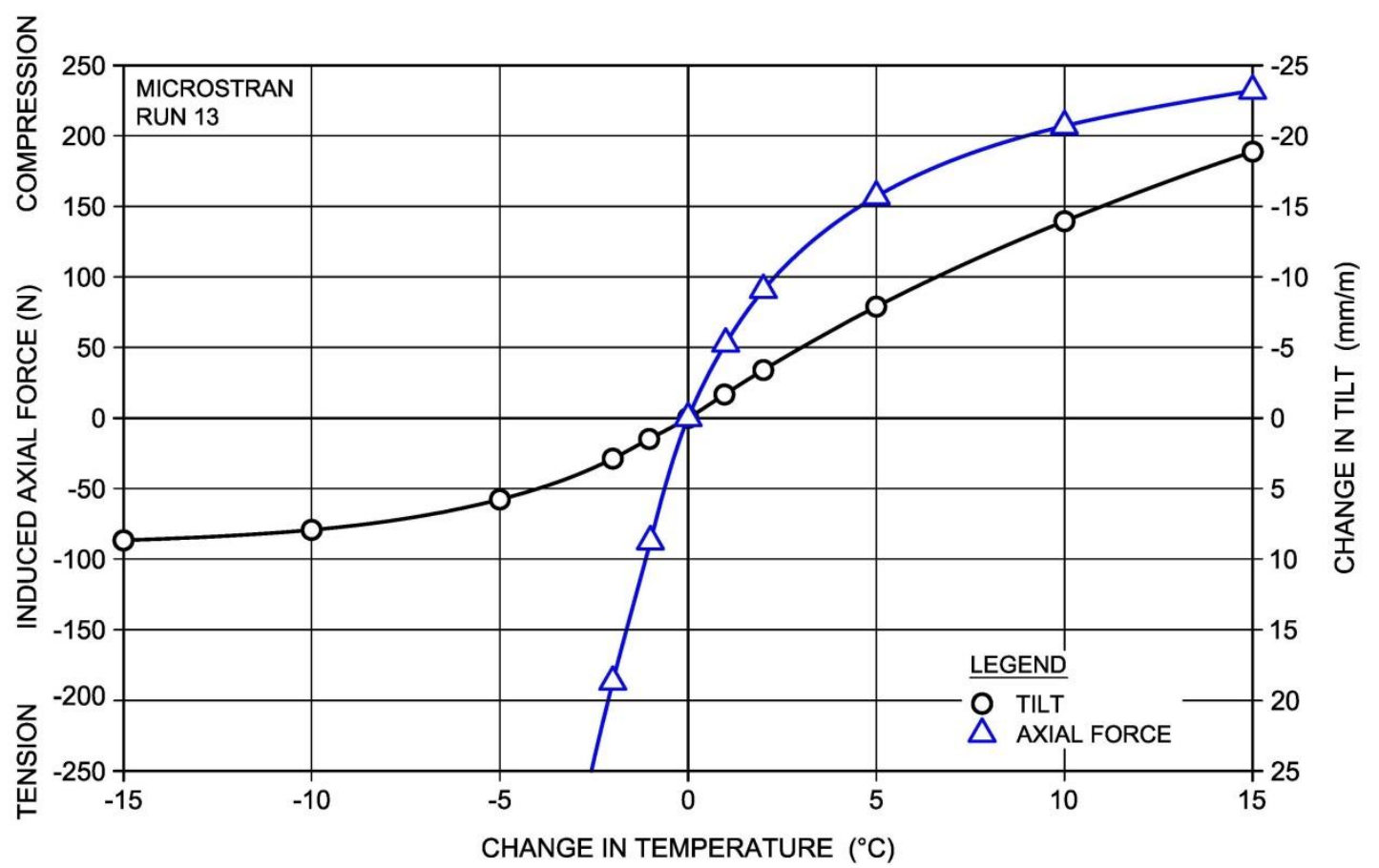

\section{Figure 7 Results of structural modelling showing changes in tilt and axial force from changes in temperature for a 2 m long, axially restrained IPI instrument}

Reduction in temperature results in tension and a straightening of the extension tubes. As the initial deflection due to self-weight is in the order of $7 \mathrm{~mm}$, the sensitivity of tilt to a reduction in temperature is limited by the fact that the tube can only straighten by this amount. Figure 7 shows a sensitivity of up to $1.4 \mathrm{~mm} / \mathrm{m} /{ }^{\circ} \mathrm{C}$, decreasing with lower temperatures. Induced tensile forces of over $2,000 \mathrm{~N}$ are calculated for a temperature change of $-15^{\circ} \mathrm{C}$.

\section{Laboratory work}

\subsection{Thermomechanical response}

A series of laboratory-based experiments were devised to verify the results of the structural model and improve the level of confidence in the findings.

The experiments involved use of a similar IPI to those used for the tunnel project (i.e. with a gauge length of $2 \mathrm{~m}$ ). The extension tube used in the experiments was one of those retrieved from the tunnel project. It was found to be slightly bent, with a central deviation of about $5 \mathrm{~mm}$.

The assembled instrument was attached to a loading frame and fixed from axial movement at each end. The fixing details at the sensor end and at the end of the extension tube allowed rotation in the vertical plane, similar to the standard installation detail.

The frame comprises two parallel steel tubes separated by a gap of $200 \mathrm{~mm}$. Each tube has an outside diameter of $32 \mathrm{~mm}$ and an inside diameter of $27 \mathrm{~mm}$. These were joined at each end by two $50 \times 8 \mathrm{~mm}$ steel plates which were welded to the tubes.

A $50 \mathrm{kN}$ load cell was fitted between the end of the sensor and the frame to monitor axial forces in the instrument.

A purpose-built flexible insulated duct was placed around the instrument as shown in Figure 8. The purpose of this was to allow control of the temperature of the instrument without influencing the temperature of the loading frame. The ducting was joined to form a loop so that air could be constantly circulated by a small fan. This ensured that a uniform temperature was experienced by the whole instrument. 
A $25 \mathrm{~W}$ incandescent globe was placed next to the fan, allowing a temperature rise of up to $15^{\circ} \mathrm{C}$ above ambient to be achieved within a few hours.

Three temperature sensors were employed to monitor the components:

- IPI sensor within the insulated duct.

- IPI sensor attached to the loading frame (i.e. outside the duct).

- VWP sensor placed inside the insulated duct (at the far end of the extension tube).

Data loggers were used to record the tilt, temperature, and displacement readings at intervals of between one and five minutes.

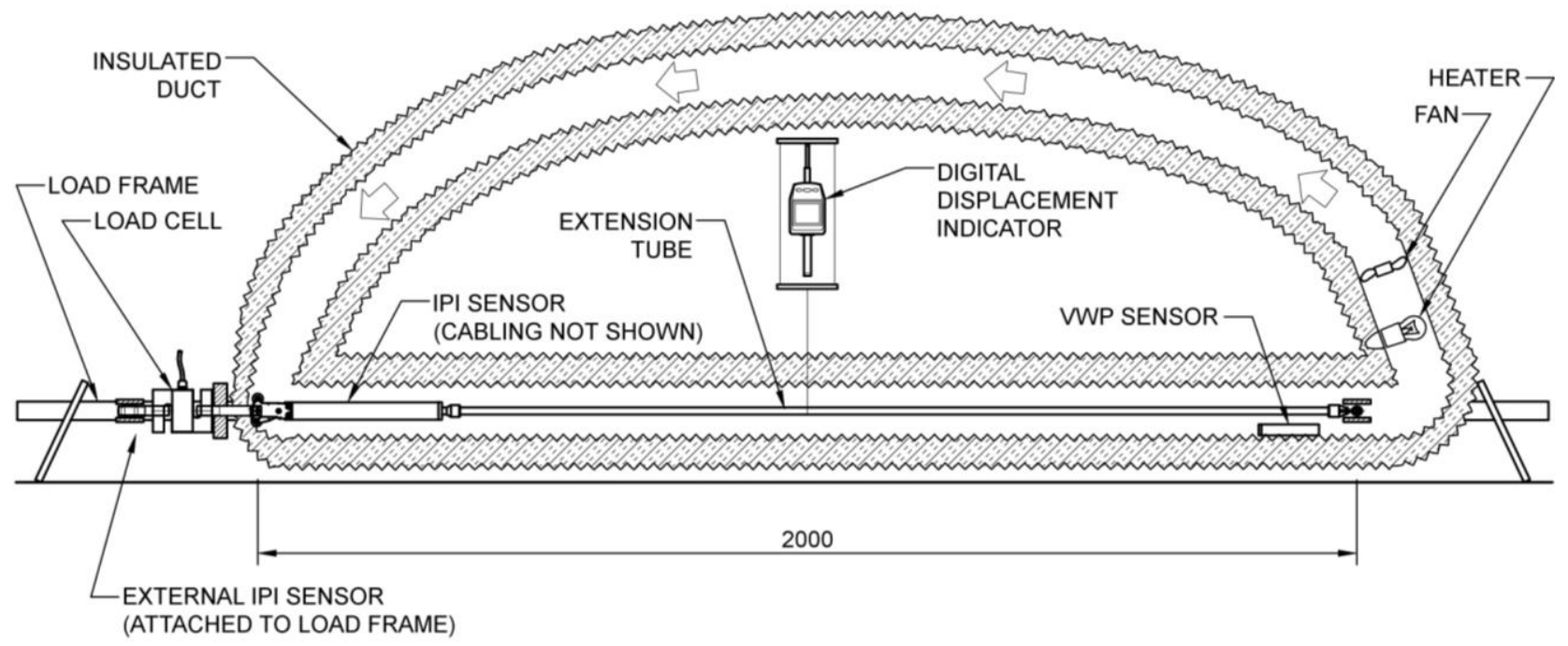

Figure 8 Experimental set-up, showing IPI fixed within a rigid loading frame, and thermally isolated from it

Three experiments were performed, each starting from a different initial axial force. The axial force was adjusted by screwing the rod end in or out of the threaded end connector, and monitoring the induced force with the load cell. Once the initial load was set, the instrument was restrained from further axial deformation.

The test result for the $10 \mathrm{~N}$ initial axial force is shown in Figure 9. This shows that the temperature experienced by the IPI sensor increased by about $12^{\circ} \mathrm{C}$ over a period of two hours, before gradually subsiding in the next several hours. This was repeated two or three times for each of the three applied axial forces.

Figure 9 also shows that the measured tilt responded in a similar manner to the temperature change, increasing by about $10 \mathrm{~mm} / \mathrm{m}$. Figure 10 shows the tilt relative to the change in temperature for each of the three experiments. The sensitivity for the three tests ranged from 0.55 to $0.70 \mathrm{~mm} / \mathrm{m} /{ }^{\circ} \mathrm{C}$, with the higher values corresponding to the lower initial forces. This reduction in sensitivity is consistent with the results of the structural model.

The sensitivity values also compare favourably with the field results shown in Figure 5.

The axial forces were not able to be measured precisely due to the relatively large capacity load cell used. For the 10 and $50 \mathrm{~N}$ tests the axial force increased by 180 to $190 \mathrm{~N}$, whereas for the $200 \mathrm{~N}$ test the axial force increased by only $80 \mathrm{~N}$. This response is similar to the results from the structural model in Figure 7. 


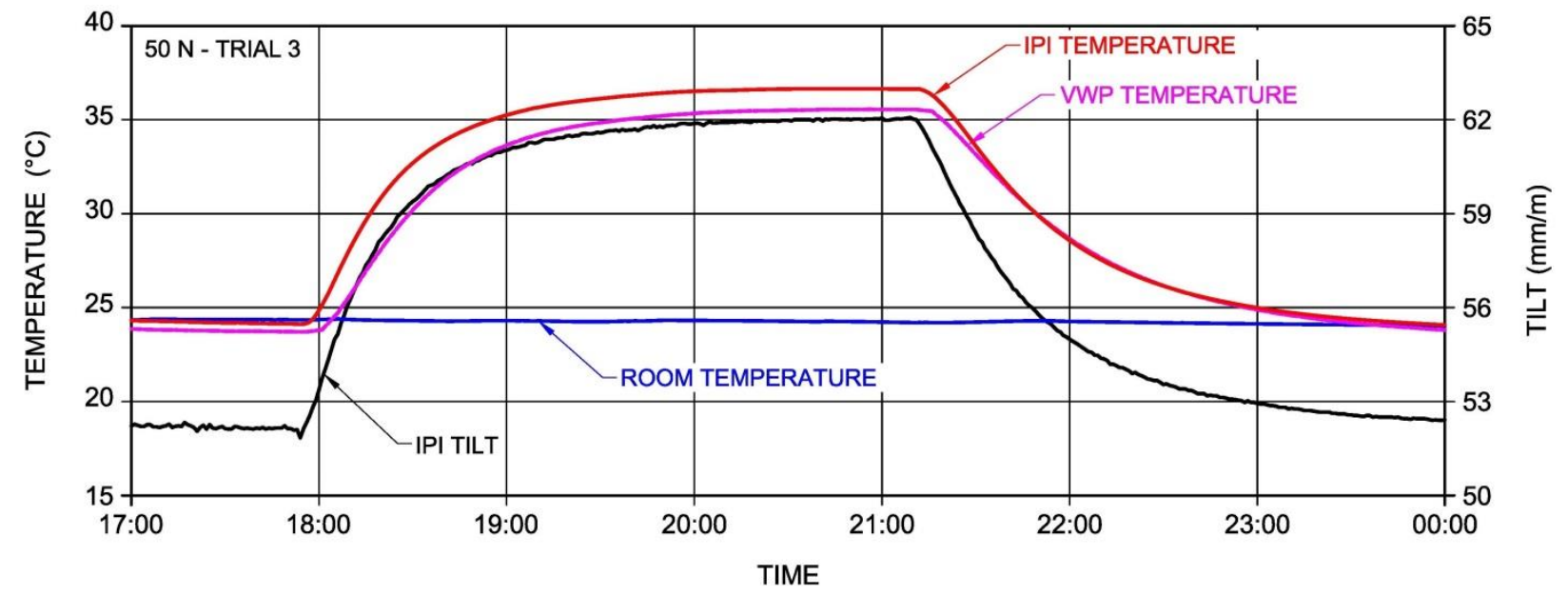

Figure 9 Experimental result for test involving a $50 \mathrm{~N}$ initial axial compressive force
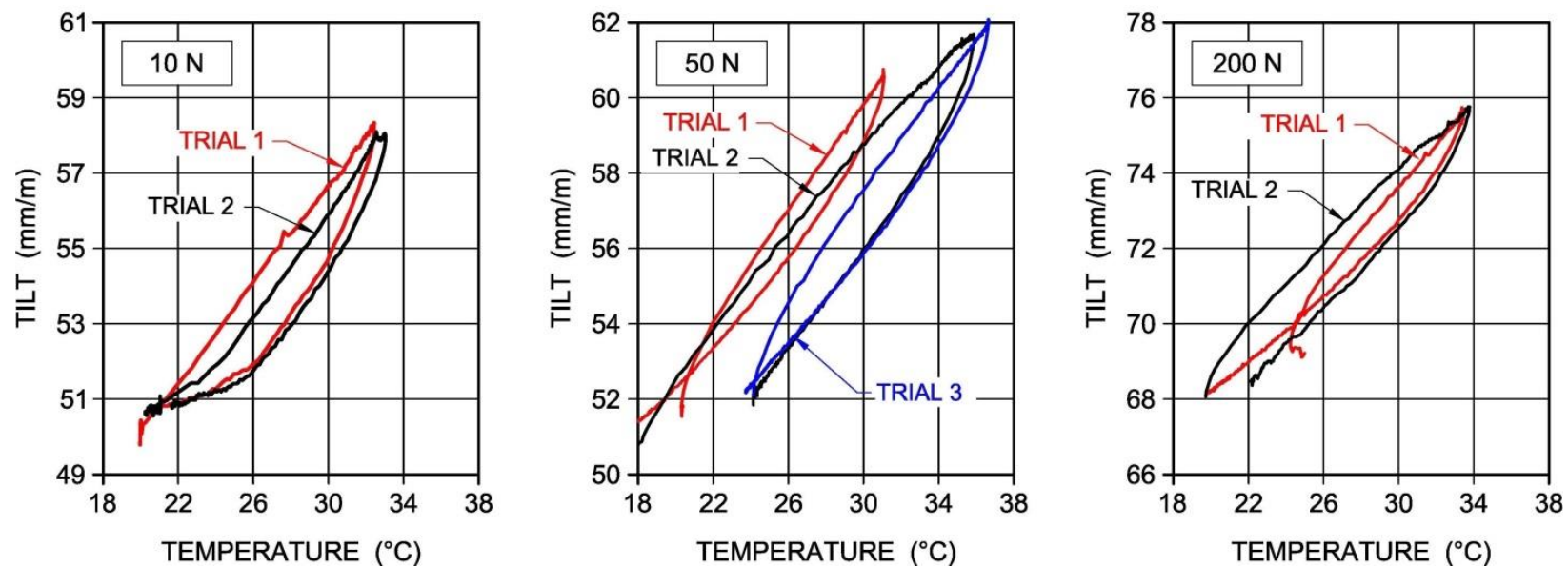

\section{Figure 10 Correlation between tilt measured by the IPI and temperature for the three tests}

The stiffness of the loading frame (including load cell and connecting rods) was checked by additional structural analysis. Figure 6 shows the model that included the frame. This analysis indicated that the axial stiffness of the frame was in the order of $20 \mathrm{kN} / \mathrm{mm}$, which was sufficiently high so as to have negligible effect on the experimental results.

\subsection{Wheel friction}

Wheel friction was determined by placing a single IPI instrument inside a $3 \mathrm{~m}$ length of inclinometer casing. The casing used was $70 \mathrm{~mm}$ ABS casing manufactured by Geotechnical Systems Australia.

As each instrument only has a single pair of wheels, the far end of the rod was suspended by a short length of string oriented perpendicular to the casing axis, such that it provided no axial resistance (prior to the wheels slipping). The wheels were placed in grooves aligned in the vertical direction.

One end of the casing was attached to a pulley system to allow it to be gradually raised. The slope of the casing at which the sensor first slipped was recorded. This exercise was repeated five times, with slip angles of between $45.5^{\circ}$ and $57.5^{\circ}$ recorded, and an overall average angle of $51.7^{\circ}$.

The sensor, cabling and tubing had a combined mass of $1.40 \mathrm{~kg}$. From these values, the axial force required to overcome the friction from one pair of wheels is calculated to be about $11 \mathrm{~N}$.

Therefore, to install the 40 instruments used for the tunnel project, the total resistance was likely in the order of $440 \mathrm{~N}$ (equivalent to approximately $45 \mathrm{~kg}$ force). This appears consistent with the installer's 
recollection that two men were required to push the IPI into the casing. Once all the instruments were in place and the force at the end released, the axial compression would tend to redistribute, with a 'locked-in' axial compressive force of about $11 \mathrm{~N}$ in the instruments at the portal, increasing linearly to the central instruments where the locked-in force would be in the order of $220 \mathrm{~N}$.

This triangular distribution of force bears some similarities with the range of tilts recorded on the tunnel project during the Christmas break (Figure 4). It suggests that the degree of tilt that occurred was limited by the restraint afforded by the positon of each instrument within the 'string' of 40 instruments.

The structural modelling predicted an induced axial compressive force of $220 \mathrm{~N}$ for an increase in temperature of $13^{\circ} \mathrm{C}$. This value suggests that the wheel assemblies in the middle of the tunnel may have been fully restrained, whereas the instruments located closer to each portal would have slipped to some degree. It also means that some of the slippage would have been towards the far portal where no excavation had yet occurred. This would explain the change in tilt which occurred for the instruments located ahead of the tunnel face in Figure 4.

\section{Implications and recommendations for future installations}

The measured wheel friction of about $11 \mathrm{~N}$ per wheel assembly means that even assemblies comprising of just a few instruments would result in significant axial restraint to each instrument, especially the ones in the middle. Where the instrument temperatures remain stable, such restraint is unlikely to cause significant error.

Figure 11 presents an assessment of the thermal mechanical error expressed in terms of cumulative deviation, based on the findings presented in this paper. It considers various length assemblies of IPI instruments (of $2 \mathrm{~m}$ gauge length) subject to temperature increases. The error is based on the analysis results shown in Figure 7, a wheel friction of $11 \mathrm{~N}$, and assumes that all instruments experience the same temperature variation. It indicates that greater length installations result in greater errors, and that the error increases with the change in temperature up to a limiting value. The limiting value corresponds to slippage of the wheels.

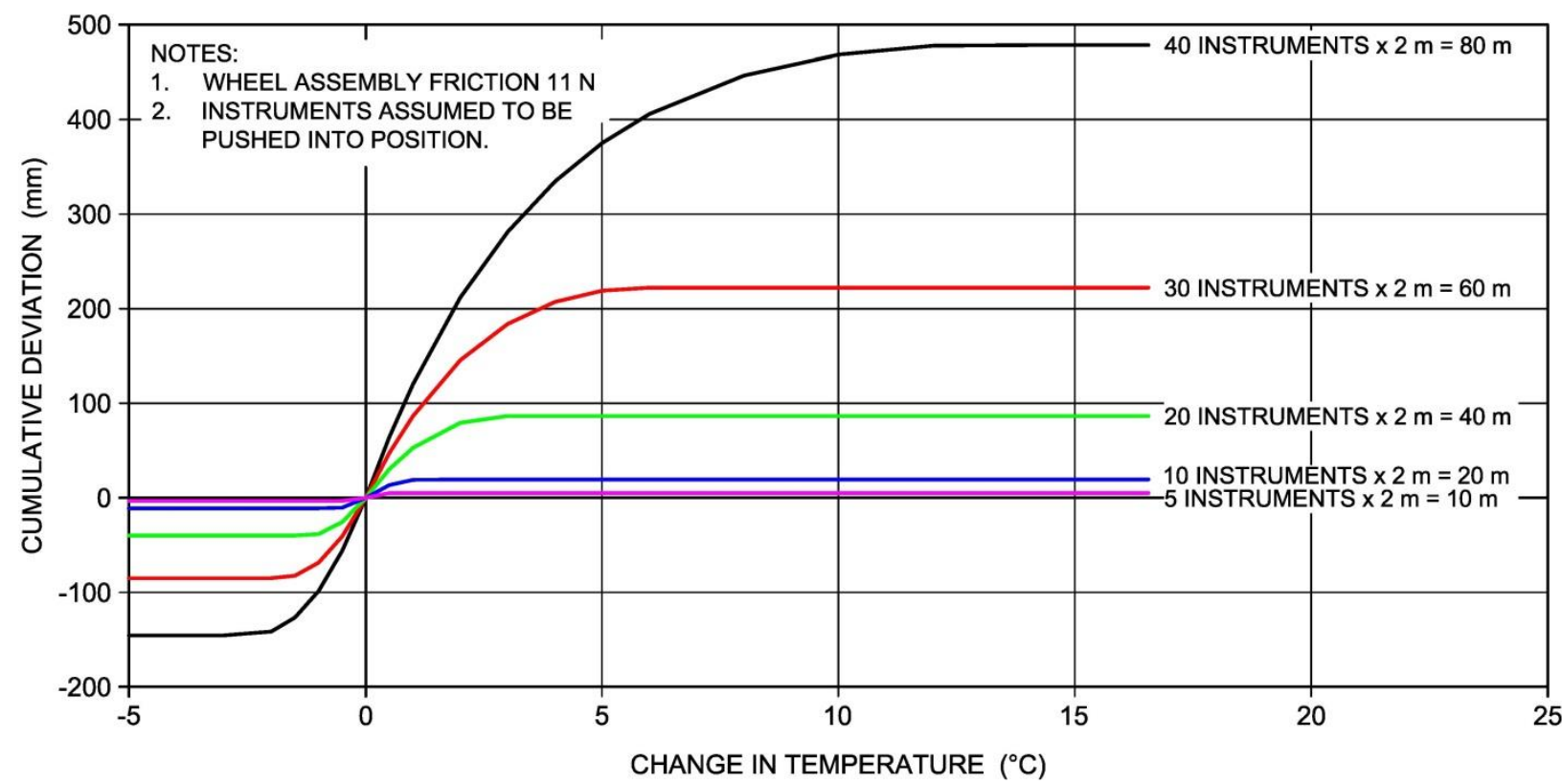

\section{Figure 11 Thermomechanical error expressed in terms of cumulative deviation as a function of temperature change and number of instruments}

This graph may be compared with the cumulative deviation of $345 \mathrm{~mm}$ described previously in Section 3 . This was for 40 instruments, with those above the excavated length of tunnel experiencing a temperature increase of about $10^{\circ} \mathrm{C}$. Figure 11 suggests an error of up to $470 \mathrm{~mm}$. The difference may be partially 
explained by the fact that about four of the instruments experienced smaller temperature changes as they were located in the portion of the tunnel yet to be excavated.

Potential modifications to the instruments and installation details to reduce the severity of this effect include:

1. Avoid use of horizontal IPI installations in locations where temperature changes may occur.

2. Use a lower friction wheel and casing combination.

3. Apply an axial tensile force (e.g. springs) in excess of the total wheel frictional force to ensure that the whole instrument remains in tension (i.e. analogous to an IPI suspended in a vertical installation).

4. Incorporate a slot of a few millimetres length in the sensor to allow thermal expansion to occur. The instrument string would need to be initially tensioned, and the bolt detailed to allow it to slide along this slot.

5. Employ an extension tube with greater bending stiffness in the vertical compared to the lateral direction, so that bending due to thermal expansion occurs laterally, and thus doesn't affect the tilt in the vertical plane.

6. Locate the tilt sensors in the centre of a symmetrical instrument, so that bending of the instrument does not alter the midspan tilt.

It is noted that the analysis undertaken in this paper relates specifically to instruments with a gauge length of $2 \mathrm{~m}$. The use of shorter gauge lengths will be less susceptible to this error.

It is unlikely that the SWRL data can be corrected for this thermomechanical error due to the variability in the force at which the wheel friction is overcome, and the associated 'shunting' of adjacent instruments as each wheel assembly slips in the casing.

\section{Conclusion}

The errors observed in the recent tunnelling project are attributed to two main factors:

- Friction between the wheels of the instrument and the inclinometer casing which effectively restrained axial movement. This factor was exacerbated by the large number of instruments employed.

- Significant temperature variations experienced during tunnel construction (up to $13^{\circ} \mathrm{C}$ ).

These factors contribute to a thermomechanical mechanism in which the extension bars linking the instruments bend due to thermal expansion. This behaviour is only possible if the instruments are prevented from axial movement along the inclinometer casing. It results in a real tilt of the instrument sensor which is independent of the deformation of the casing. The sensor therefore indicates movement that does not represent that of the casing.

The mechanism has been verified by both structural modelling and laboratory experiments. Both indicate a sensitivity of the measured tilt to changes in temperature similar to that assessed from the field data.

An additional experiment to measure the wheel friction confirmed the presence of significant axial restraint for a single instrument prior to slippage of the wheels. Use of multiple instruments joined together results in those in the middle being subject to greater restraint, and thus increased tilt error.

The magnitude of the error from this mechanism has been quantified in terms of the temperature change and the number of instruments connected together. The calculated error compares favourably with the error from the SWRL project.

A number of modifications to the instrument design and installation procedures are also proposed to avoid this problem recurring in future installations. 


\section{Acknowledgement}

The author thanks Colin Viska of Slope Indicator Co. for his encouragement in solving this problem and for the loan of instrumentation used in the experimental phase of the work. The author also expresses his appreciation to Steve Garlinge (formerly of Lynton Survey) and other Lynton Survey personnel for their professionalism during the difficult period when the problem first manifested, and their continuing interest and help in resolving it following completion of the project. Thanks also to Kim Chew of Eastwood Air Conditioning for the custom-built insulated ducting used in the laboratory work.

\section{References}

Clarke, SJ \& Walker, CS 2014, 'Deformation mechanisms of the South West Rail Link underpass beneath the Hume Highway', Proceedings of the 15th Australasian Tunnelling Conference 2014, The Australasian Institute of Mining and Metallurgy, Melbourne, pp. 631-640.

Hill, J, Nievergelt, R \& Chapman, B 2014, 'Design and construction of Sydney's South West Rail Link Hume Highway underpass', Proceedings of the 15th Australasian Tunnelling Conference 2014, The Australasian Institute of Mining and Metallurgy, Melbourne, pp. 375-386. 